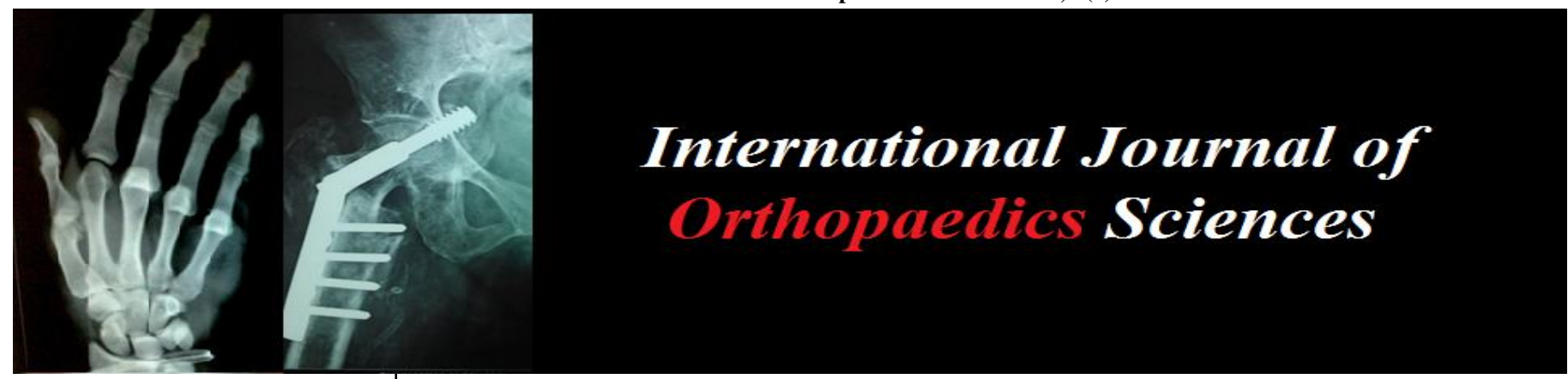

E-ISSN: 2395-1958

P-ISSN: 2706-6630

IJOS 2021; 7(2): 673-679

(C) 2021 IJOS

www.orthopaper.com

Received: 13-02-2021

Accepted: 15-03-2021

Dr. Saranjeet Singh Jagdev Head and Professor, Department of Orthopaedics, Pramukhswami Medical College, Karamsad,

Gujarat, India

Dr. Utsav V Pate

$3^{\text {rd }}$ Year Resident

Department of Orthopaedics,

Pramukhswami Medical College,

Karamsad, Gujarat, India

Dr. Vinit Brahmbhat

$2^{\text {nd }}$ Year Resident, Department

of Orthopaedics, Pramukhswami

Medical College, Karamsad,

Gujarat, India

Dr. Dharmik Patel

$1^{\text {st }}$ Year Resident, Department of

Orthopaedics, Pramukhswami

Medical College, Karamsad,

Gujarat, India
Corresponding Author:

Dr. Utsav V Patel

$3^{\text {rd }}$ Year Resident

Department of Orthopaedics,

Pramukhswami Medical College,

Karamsad, Gujarat, India

\section{Analysis and comparison of functional and radiological outcomes of distal end radius fractures managed with operative interventions}

\author{
Dr. Saranjeet Singh Jagdev, Dr. Utsav V Patel, Dr. Vinit Brahmbhatt and \\ Dr. Dharmik Patel
}

DOI: $\underline{\text { https://doi.org/10.22271/ortho.2021.v7.i2i.2690 }}$

\section{Abstract}

Context: Distal end radius fractures are among the commonest fractures encountered in public health care. These injuries are associated with osteoporosis, articular damage, comminution and complex fracture pattern. These fractures should be managed according to fracture configuration and functional demand of patient.

Material and Methods: 110 patients with distal end radius fractures were managed with different surgical fixation. Out of them 58 were operated by locking plates, 44 were operated by percutaneous $\mathrm{k}$ wire pinning and external fixation was done in 8 patients. Mean age of study population was 46.4 year (range 20-75year) with slight male dominance. All patients were assessed post operatively by clinical and radiological methods in forms of DASH score, VAS pain score, range of motion at wrist joint, operative complication of each treatment modality, pinch and grip strength of both hands.

Results: Patients managed with plating had significantly better function, strength and range of motion as compared with patients operated with K-wiring or distractor in all 8 types of fractures $(\mathrm{p}<0.05)$. Mean DASH score, VAS pain score, range of motion and grip strengths were much better in locking plate group compared to $\mathrm{k}$ wire pinning and external fixation. Locking plate was also found better at restoring radiological parameters (radial tilt, radial inclination and radial height) as compared to other methods. Collapse in radial height was more in k-wiring group in patients with osteoporotic bones.

Conclusion: Improved understanding of fracture pattern and bone quality by various radiological examination demands proper fixation to get better functional outcomes. Locking plate has superior outcome for osteoporotic bone, articular damage and complex injuries while $\mathrm{k}$ wire pinning should be used for good quality bone with less functional demand and external fixation should be reserved for open injuries and poor skin texture.

Keywords: distal radius fractures, volar locking plates, DASH score, K wire

\section{Introduction}

Distal radius fracture (DRF) remains the most common fracture encountered in health care. With increasing life expectancy, aging population, and subsequent increase in osteoporosis it has ultimately contributed to rise in the incidence of distal radius fractures, with reports of substantial increment over the past 3 to 4 decades ${ }^{[2,3]}$. Although closed reduction and conservative management by plaster application was widely practiced earlier ${ }^{[4]}$, surgical fixation of distal radius fractures enables patients to resume daily activity earlier and more independently ${ }^{[1,5]}$.

Management of DRFs has always been an area of intense research and innovation. Whereas closed reduction and percutaneous pinning and external fixation remained the mainstays of treatment in the past, open reduction and volar fixed-angle plating has become popular and has dramatically shifted the landscape in several ways. Since the end of the 20th century, the incidence of DRF surgery in general and of plating in particular have increased markedly.

DRFs have a bimodal distribution, with a peak in younger persons (18-45 years) and a second peak in older persons (>65 years). The mechanism of injury is unique to each group, with high-energy injuries being more common in the younger group and low-energy injuries being more common in the older group; this difference has implications for treatment. 
The standard DRF occurs in older patients, who have much weaker bones and can sustain a DRF from simple, low energy trauma or merely a fall. Isolated DRF's typically include Smith's, Colle's, and Die-punch, Barton's and Chauffeur's fractures and extra articular DRF ${ }^{[7]}$ As the population lives longer, the frequency of this type of fracture has increased. They are often comminuted and intra-articular fractures that often fall outside of traditional eponymous classification. Younger patients have stronger bones, and thus, more energy is required to create a fracture in these individuals. Motorcycle accidents, falls from a height, and similar situations are causes of high-energy DRFs, and such fractures must be considered to be a separate entity from the fractures in the older population. The injury to bone and soft tissue in high-energy DRFs is greater than that in typical DRFs.

It is a well-established concept that functional recovery closely parallels the accuracy of skeletal restoration. Hence the treatment modality of fixing distal radius fractures should be such that it can hold the fractured fragments in anatomic reduction till union occurs hence preventing loss of reduction as well as leads to good and early functional recovery. Goal of treating a DRFs should be to achieve a painless, congruous wrist joint with anatomic reduction of the fracture along with faster and optimum recovery of functions.

With increase in incidence of DRF'S in last 30 years the management options have also expanded remarkably. It was observed with due course of time that the invention of volar locking plate was a breakthrough step in management of DRF'S. Plating was found to an outstanding technique in maintaining anatomic reductions throughout the fracture healing process with seldom loss of reductions and hence better functional outcomes. Despite this, evidence-based guidelines for management of distal radius fractures of different types are still lacking ${ }^{[9]}$. The mainstay of this study is to compare the functional outcomes of common surgical interventions for various types of DRF'S.

\section{Materials And Methods}

This retrospective-prospective study was examined and approved by the Ethical Committee of Shree Krishna Hospital and Pramukhswami Medical College, Karamsad.

\section{Inclusion criteria}

- All operated cases of lower end radius fracture in Shree Krishna fracture from 01-01-2016 to 30-03-2020.

- $\quad$ Age of patients $>18$ years

\section{Exclusion criteria}

- Open fractures of lower end radius

- Fractures associated with other ipsilateral limb fractures

- Fractures associated with carpal bone involvement

- Isolated fracture of radial styloid

- Pathological fractures of lower end radius.

- Lower end radius fractures associated with nerve injury.

- Lower end radius fractures associated with tendon injury.

- Bilateral fractures of lower end radius.

We went through the hospital records considering the inclusion and exclusion criteria and found out 123 cases of lower end radius fractures treated surgically with various operative modalities by different orthopaedic surgeons of different experience and skills at the Shree Krishna Hospital between 01-01-2016 to 30-03-2020 out of which 110 were ready to give consent and participate in the study. We recorded the demographic data, date of injury, date of surgery, injury-surgery interval, type of operative intervention done, mode of injury and associated complications. We contacted all the patients and called for final follow up. We classified the patients radiologically according to Frykman's classification of DRFs. We examined the patients for pain, asked about their day to day activities and assessed their function and disability using DASH score. We measured the range of motion using a goniometer and pinch/grip strengths using Jamar Dynamometer. We took xrays of affected and normal both the wrist joints and assessed them for radial height, radial inclination, radial tilt, loss of reduction and correlated them with functional outcomes, pain, strengths gained and wrist range of motion gained after surgery. The functional and radiological outcomes of operated limb were compared with those of the opposite normal limb which were used as reference standard for each patient.

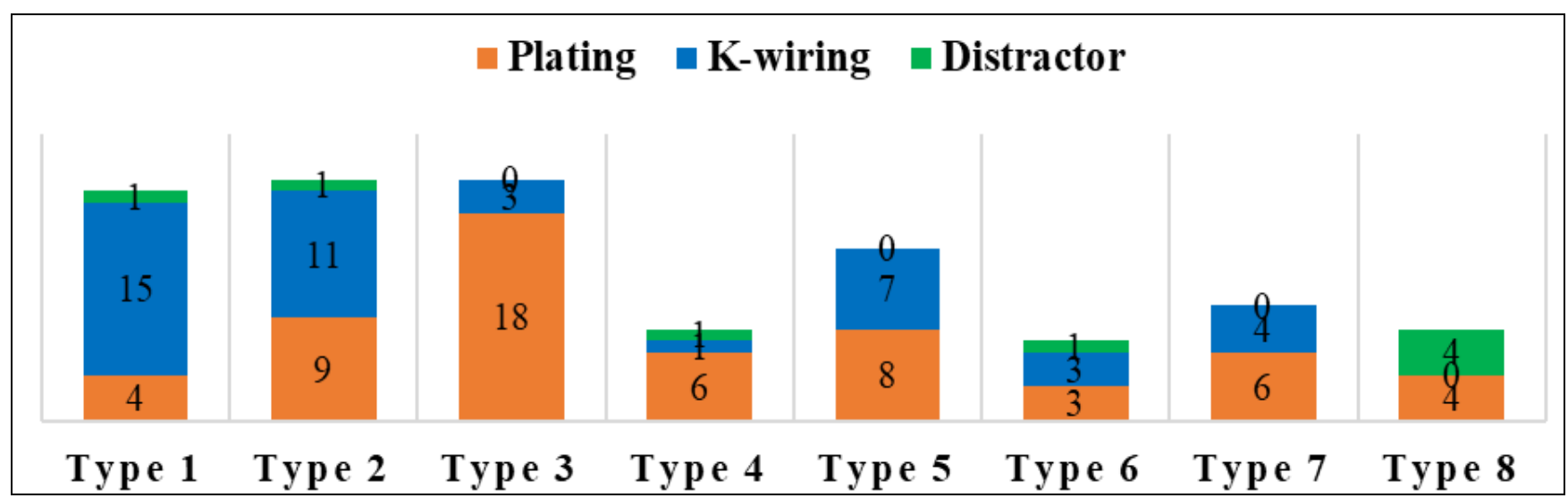

Fig 1: Types of fracture (Frykman's Classification) vs Type of operative intervention

\section{Statistical analysis}

Descriptive analysis was done to present the collected data. With the advantage of large sample size and normal distribution of data, parametric statistical methods were employed for statistical analysis. One way ANOVA test was applied to compare the DASH score, VAS pain score, percentage of range of motion gained, percentage of strength gained, radial height, radial inclination and radial tilt amongst various types of operative interventions in all the different types of fractures. A p-value of $<0.05$ was considered significant. Once significance was established, post-hoc tuckey test was used for pairwise comparison between plating vs k wiring \& plating vs distractor for all fracture types. All the analysis of data was done using STATA 14.2 software. 


\section{Results}

The average age of study population was 46.4 years (ranging from 20 to 75years). There was no sex predisposition and fractures had almost similar incidence with $43.64 \%$ in females, slightly less than males $(56.36 \%)$. There was no side predisposition either and fractures had almost similar incidence with $53.75 \%$ on left side, slightly more than right side $(46.25 \%)$

Most common mode of injury causing distal end radius fractures in our study was low energy trauma by domestic fall on outstretched hand (46\%) where majority of patients were in osteoporotic age group with poor bone quality with second most common cause being high energy trauma by road traffic accidents (37\%). Fall from height (11\%) was found to be the third most common cause of DRFs in our study followed by assault and other causes with 3\% incidence each

Plating (53\%) was found to be the most commonly performed surgery in distal end radius fractures followed by k-wiring $(40 \%)$. Out of 58 cases managed with plating, volar plating was done in $55(50 \%)$ cases and dorsal plating was done in only $3(3 \%)$ cases. Distractor $(7 \%)$ was done in only 8 cases owing to its limited indications, non-compliance and delayed rehabilitation.

By understanding the correlation between the mode of injury and type of operative intervention it was observed that majority of the patients sustaining a domestic fall had trivial injuries because of low energy trauma and hence could be easily managed with $\mathrm{k}$ wiring (29 out of 51). Whereas on the other hand those sustaining RTA had significant injuries because of high energy trauma and hence needed fixation with plating (32 out of 41). It was also observed that patients having extra articular DRFs (type 1 and type 2) were mostly treated with $\mathrm{k}$-wiring whereas all the intra-articular fractures were predominantly treated with plating. Another observation derived from this correlation is that comminuted intraarticular fractures (type 8) were treated either with plating or distractor suggesting inefficiency of $\mathrm{k}$ wiring in giving acceptable reductions in such complex fractures.

Out of 110 patients, almost $33(30 \%)$ patients had no postoperative complications out of which 27 were treated with plating suggesting satisfactory results. $17(15 \%)$ had mild occasional pain with no functional disability due to pain. 11 subjects developed wrist stiffness, and 7 subjects reported pain while performing specific activities involving extreme of movements. 14 patients had implant related issues out of which 10 were operated with plating and 4 of them opted for implant removal after fracture union. 4 cases suffered from pin tract infections out of which 3 were diabetic. 3 patients with $\mathrm{k}$-wiring ended up in having loss of reduction.

Table 1: Comparison of assessment parameters between Plating group and K-wiring group

\begin{tabular}{|c|c|c|c|}
\hline Assessment parameters & Plating group & K-wiring group & p value \\
\hline & (Mean) & (Mean) & \\
\hline DASH score & 2.76 & 11 & $<0.05$ \\
\hline VAS pain score & 0.43 & 1.29 & $<0.05$ \\
\hline \% gain in movements & 90.18 & 83.75 & $<0.05$ \\
\hline \% gain in strengths & 89.89 & 73.43 & $<0.05$ \\
\hline Difference in radial inclination & 1.82 & 5.94 & $<0.05$ \\
\hline Difference in radial height & 0.86 & 4.04 & $<0.05$ \\
\hline Difference in radial tilt & 2.45 & 7.47 & $<0.05$ \\
\hline
\end{tabular}

Table 2: Comparison of assessment parameters between Plating group and Distractor group

\begin{tabular}{|c|c|c|c|}
\hline Assessment parameters & Plating group & Distractor group & p value \\
\hline & (Mean) & (Mean) & \\
\hline DASH score & 2.76 & 17.23 & $<0.05$ \\
\hline VAS pain score & 0.43 & 1.75 & $<0.05$ \\
\hline \% gain in movements & 90.18 & 74.65 & $<0.05$ \\
\hline \% gain in strengths & 89.89 & 61.27 & $<0.05$ \\
\hline Difference in radial inclination & 1.82 & 11.91 & $<0.05$ \\
\hline Difference in radial height & 0.86 & 7.5 & $<0.05$ \\
\hline Difference in radial tilt & 2.45 & 18.36 & $<0.05$ \\
\hline
\end{tabular}

Mean DASH score in plating group was 2.76 as compared to 11 in k-wiring group and 17.23 in external fixator group. Similarly, patients in plating group gained $90 \%$ of total range of motion as compared to $84 \%$ in k-wiring group and $75 \%$ in external fixator group. When total gain in grip strengths was measured it was found that plating group gained almost $90 \%$ of strength as compared to opposite limb whereas, k-wiring group gained only $73 \%$ strength and external fixator group gained only $61 \%$ of strength. Plating was also found better at restoring radiological parameters. Mean difference in radial height in plating group was $0.86 \mathrm{~mm}$ as compared to $4.04 \mathrm{~mm}$ and $7.5 \mathrm{~mm}$ in k-wiring and external fixator groups respectively. Mean difference radial inclination in plating group was 1.82 degrees as compared to 5.94 degrees in $\mathrm{k}$ wiring group and 11.91 degrees in external fixator group. Similarly, patients in plating group had only 2.45 degrees of difference in radial tilt as compared to 7.47 degrees in $\mathrm{k}$ wiring group and 18.36 degrees in external fixator group. Hence, it can be concluded that plating has better results than $\mathrm{k}$-wiring as well as distractor, when compared on the grounds of functionality, range of motion, post-operative pain, strength and radiological parameters. 
Table 3: Fracture type wise comparison between various types of intervention

\begin{tabular}{|c|c|c|c|c|c|c|c|c|}
\hline \multirow{2}{*}{ Type of fracture } & \multirow{2}{*}{ Type of intervention } & \multicolumn{7}{|c|}{ Assessment parameters (mean) } \\
\hline & & DASH & VAS & \% mov. gained & \% st. gained & RI diff. & RH diff. & RT diff. \\
\hline \multirow{3}{*}{ Type $1(n=20)$} & Plating $(n=4)$ & 1.89 & 0 & 88.7 & 94.52 & 1.3 & 0.5 & 1.5 \\
\hline & K-wiring $(n=15)$ & 11.04 & 1.2 & 84.82 & 74.83 & 6.44 & 3.73 & 6.05 \\
\hline & Distractor $(\mathrm{n}=1)$ & 17.24 & 1 & 76.84 & 68.97 & 9.2 & 8 & 22.3 \\
\hline \multirow{3}{*}{ Type $2(n=21)$} & Plating $(\mathrm{n}=9)$ & 3.3 & 0.33 & 92.17 & 89.67 & 2.72 & 0.77 & 3.07 \\
\hline & K-wiring $(\mathrm{n}=11)$ & 11.51 & 1.36 & 81.43 & 67.59 & 7.12 & 4.81 & 6.47 \\
\hline & Distractor $(\mathrm{n}=1)$ & 15.51 & 2 & 76.5 & 63.16 & 3.7 & 8 & 16.3 \\
\hline \multirow{3}{*}{ Type $3(n=21)$} & Plating $(\mathrm{n}=18)$ & 3.03 & 0.55 & 90.33 & 88.58 & 1.57 & 0.77 & 1.72 \\
\hline & K-wiring $(n=3)$ & 10.88 & 1.33 & 85.83 & 79.59 & 3.8 & 3.33 & 6.63 \\
\hline & Distractor & - & - & - & - & - & - & - \\
\hline \multirow{3}{*}{ Type $4(n=8)$} & Plating $(n=6)$ & 2.93 & 0.16 & 90.41 & 92.34 & 2 & 1.16 & 3.91 \\
\hline & K-wiring $(\mathrm{n}=1)$ & 9.82 & 1 & 81.16 & 76.19 & 4.5 & 3 & 3.5 \\
\hline & Distractor $(\mathrm{n}=1)$ & 20.83 & 2 & 65.85 & 57.89 & 17.7 & 6 & 15.2 \\
\hline \multirow{3}{*}{ Type $5(\mathrm{n}=15)$} & Plating $(\mathrm{n}=8)$ & 2.66 & 0.25 & 89.08 & 90.1 & 1.13 & 0.75 & 2.51 \\
\hline & K-wiring $(n=7)$ & 10.5 & 1 & 83.98 & 75.66 & 4.18 & 3 & 8.65 \\
\hline & Distractor & - & - & - & - & - & - & - \\
\hline \multirow{3}{*}{ Type $6(n=7)$} & Plating $(n=3)$ & 1.42 & 0.33 & 91.63 & 84.46 & 1.66 & 0.33 & 3.3 \\
\hline & K-wiring $(n=3)$ & 10.62 & 2 & 85.2 & 71.28 & 7.7 & 4.33 & 9.33 \\
\hline & Distractor $(\mathrm{n}=1)$ & 23.21 & 3 & 62.47 & 51.61 & 17.3 & 9 & 6 \\
\hline \multirow{3}{*}{ Type $7(n=10)$} & Plating $(\mathrm{n}=6)$ & 2.35 & 0.83 & 89.01 & 89.38 & 2.46 & 1.66 & 2.18 \\
\hline & K-wiring $(n=4)$ & 10.96 & 1.5 & 83.7 & 76.72 & 4.5 & 5.5 & 13.72 \\
\hline & Distractor & - & - & - & - & - & - & - \\
\hline \multirow{3}{*}{ Type $8(n=8)$} & Plating $(n=4)$ & 2.74 & 0.75 & 89.04 & 86.75 & 1.77 & 0.75 & 2.8 \\
\hline & K-wiring & - & - & - & - & - & - & - \\
\hline & Distractor $(n=4)$ & 15.26 & 1.5 & 78.89 & 62.15 & 11.85 & 7.25 & 21.77 \\
\hline
\end{tabular}

\section{Summary-}

DASH $=$ Disabilities of arm, shoulder and hand score

VAS $=$ Visual analogue scale pain score

$\%$ mov. gained $=$ Percentage of movements gained

$\%$ st. gained $=$ Percentage of strength gained

$\mathrm{RI}$ diff. $=$ Difference in radial inclination

RH diff. $=$ Difference in radial height

As shown in the above table, when comparison was done on the basis of assessment parameters between the plating group versus k-wiring group \& plating group versus distractor group for individual fracture types in order to remove the bias of complex fracture patterns or simple extra-articular fracture patterns affecting the outcomes. It was observed that open reduction and internal fixation with plating was a standout modality in treatment of all the types of DRF's which gave statistically superior results with $\mathrm{p}$ value $<0.05$ in all the assessment parameters.

It was also observed that open reduction and internal fixation with plating was the only modality of treatment which was employed to treat all the 8 types of fractures which again signifies the ability of this modality in satisfactorily fixing all types of fractures as well as the confidence of different operating surgeons in the modality. Whereas on the other hand, k-wiring was not done in even a single patient of comminuted DRF (type 8) hence passively justifying its inability to achieve satisfactory reductions of fractures intraoperatively. Distractors were used in a few patients only because of limited indications, non-compliance of patients and comparatively inferior results.
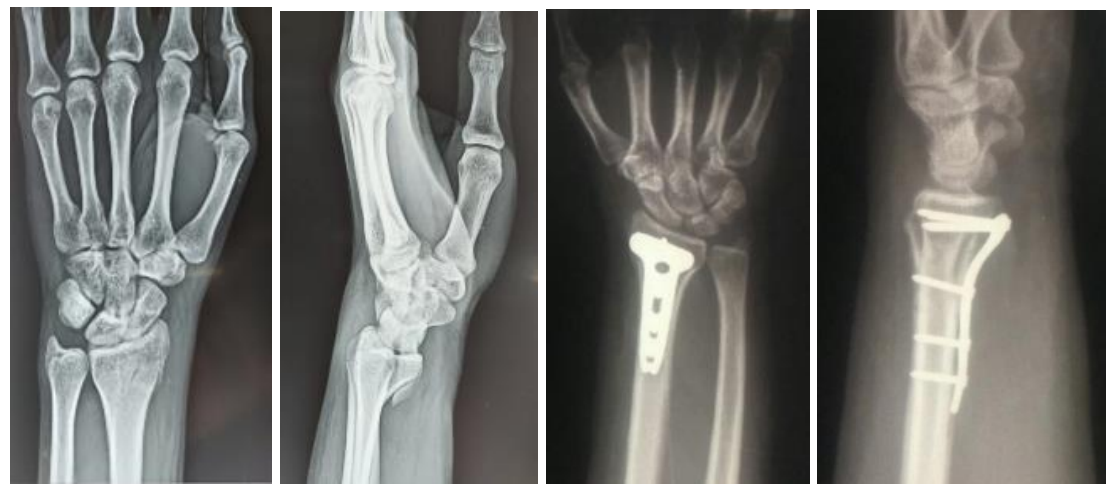

Pre-operative and post-operative $\mathrm{x}$-rays 


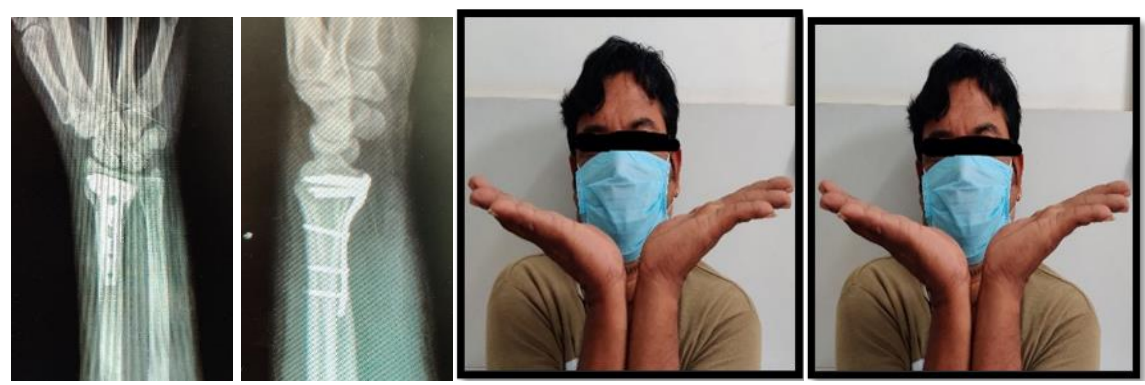

Fig 1: Radiological and clinical images of a patient operated with volar locking plate showing good outcomes
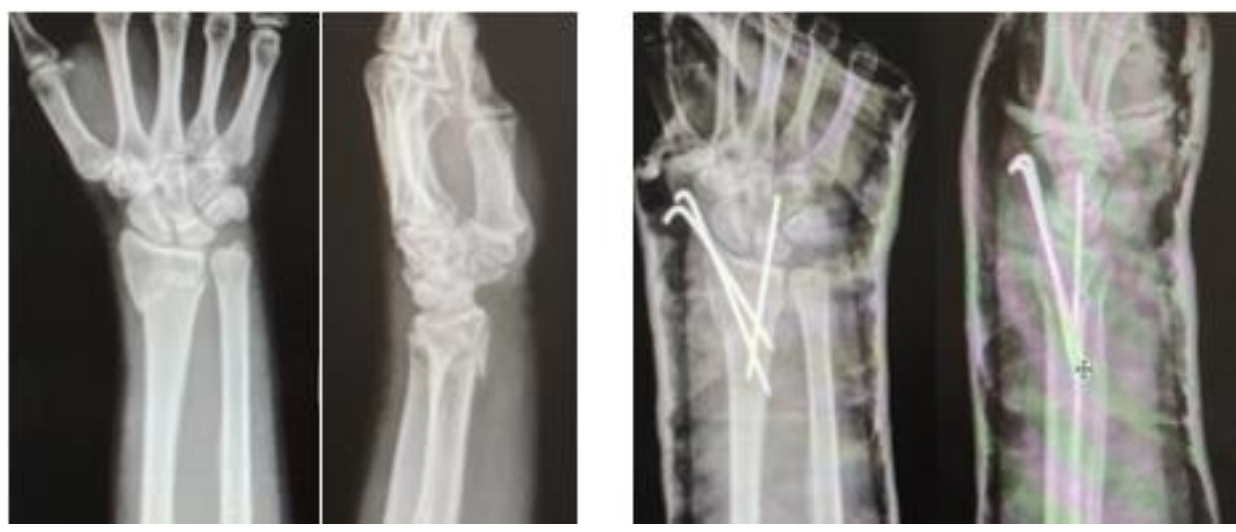

Pre-operative and post-operative $\mathrm{x}$-rays
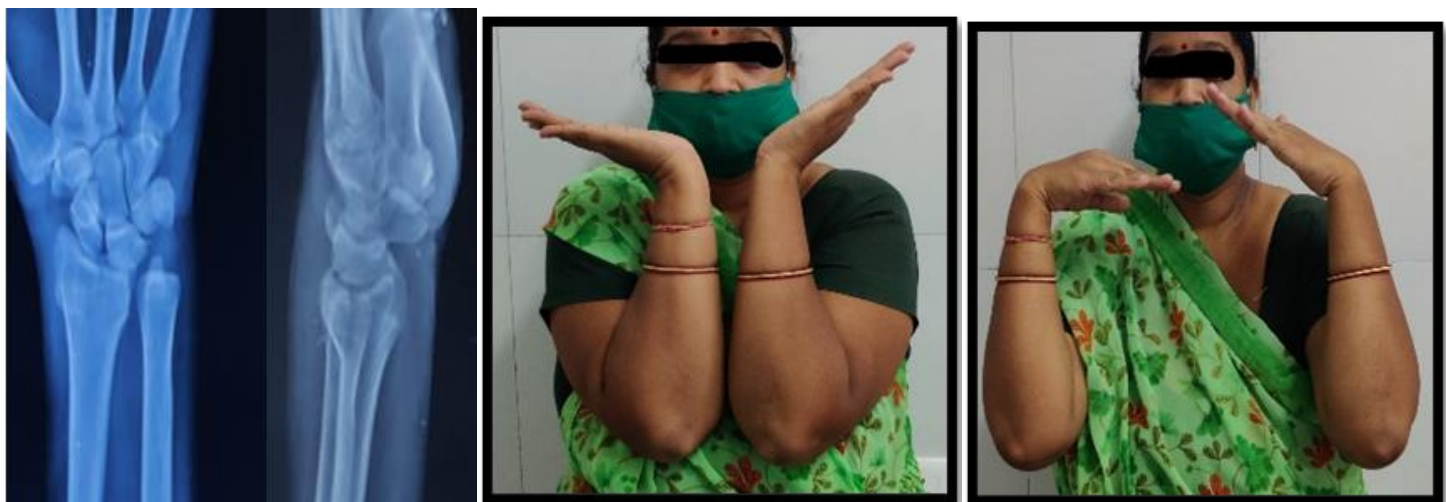

Fig 2: Radiological and clinical images of a patient operated with k-wiring showing loss of reduction and suboptimal outcomes

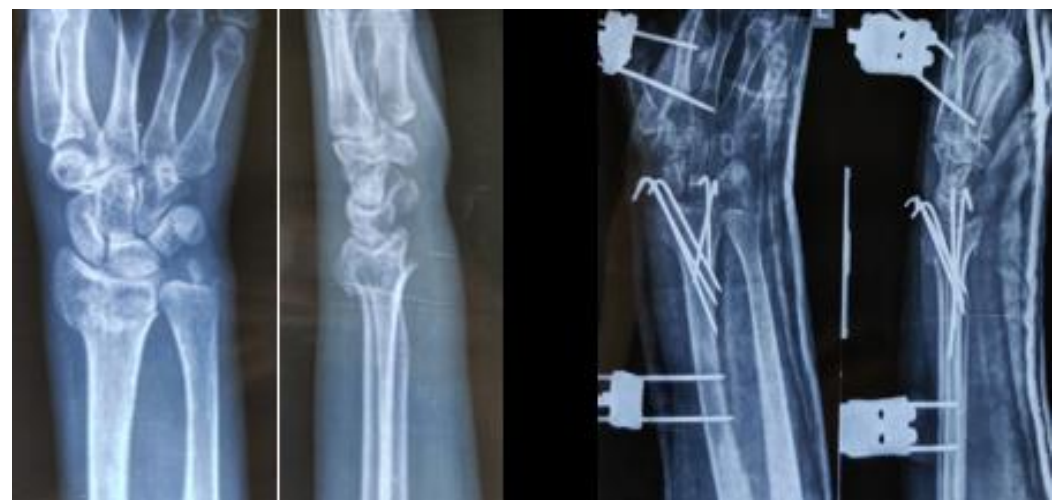

Pre-operative and post-operative $\mathrm{x}$-rays 

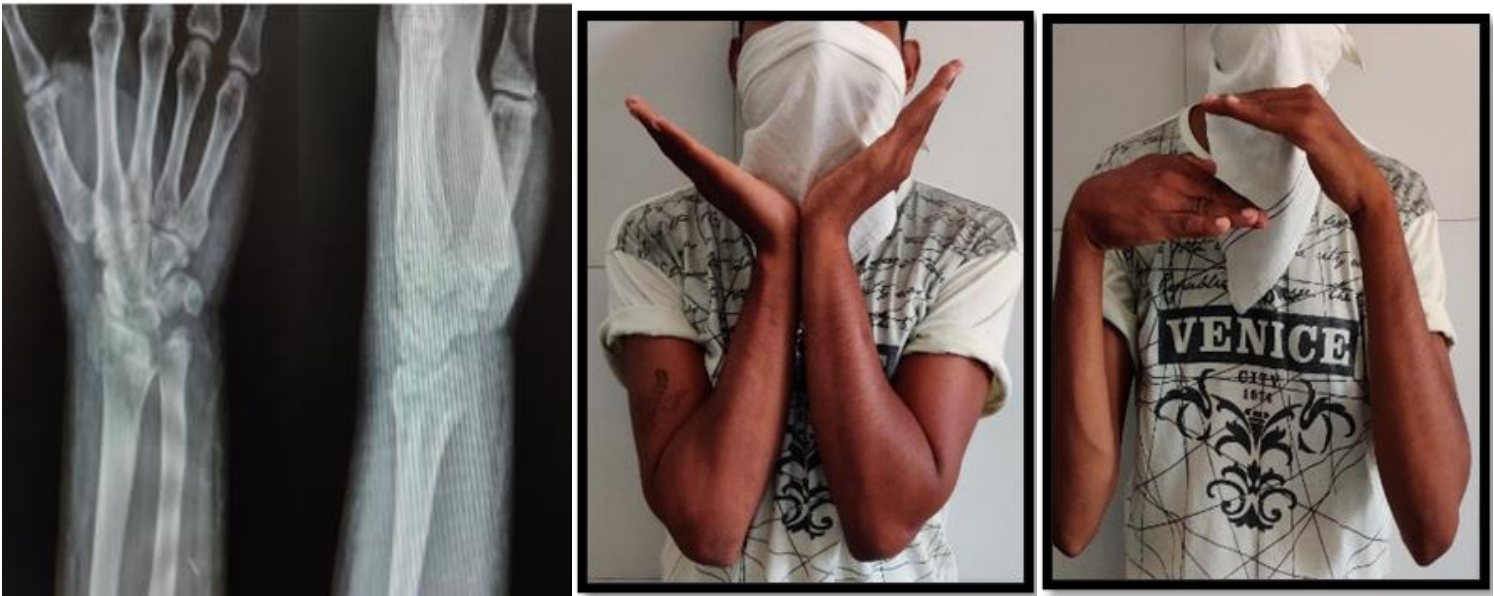

Fig 3: Radiological and clinical images of a patient operated with external fixator showing inferior outcomes

\section{Discussion}

When the functional and radiological parameters were assessed for various modalities, it was found that plating has significantly superior results as compared to k-wiring and external fixators. This conclusion from our study was also supported by numerous studies conducted in different parts of world in past. ${ }^{[11-18]}$

When the mean DASH scores were compared between plating (2.76) k-wiring (11) and distractor (17.23) groups, we noticed significantly lower DASH scores (better outcomes) with plating in concordance with various international studies ${ }^{[12-}$ 17].

When the grip strengths were measured with the help of Jamer Dynamometer keeping the strength of opposite (normal) limb as the reference standard for each patient, it was observed that plating lead to gain upto $90 \%$ of strength as compared to only $73 \%$ in k-wiring and further less only $61 \%$ in distractor. These findings were also consistent with world literature ${ }^{[12-18]}$.

Goehre et al. (2014) ${ }^{[19]}$ conducted a randomised control trial to compare the results of palmar fixed angle plate fixation with k-wiring fixation of DRF's where they concluded that subjects operated with plating gained about $95 \%$ range of motion as compared to only $87 \%$ gain in $\mathrm{k}$-wiring (control) group at 12 months follow up which is in direct agreement to our study where plating group gained $90 \%$ range of motion as compared to $84 \%$ gain in k-wiring group. Similarly, Young Hak et al. (2014) ${ }^{[20]}$ conducted a study and concluded that plating group gained significant range of motion at 3 months and 6 months follow up as compared to external fixator group which is in correlation of our study.

Goehre et al. (2013) ${ }^{[19]}$, Karantana et al. (2013) ${ }^{[14]}$ and Rizzo et al. (2007) ${ }^{[10]}$ concluded in their respective studies that postoperative radiological parameters significantly affect the functional outcomes in DRF's. Moreover, all of these also inferred that plating was way better than any other modality in maintaining the radial inclination, radial height and radial tilt till union. On the other hand $11 \%$ patients operated with $\mathrm{k}$ wiring showed loss of reduction in Goehre et al.'s study ${ }^{[19]}$, similarly in our study too, 3 patients treated with closed reduction and external fixation modalities had to suffer loss of reduction and ended up in malunited fracture resulting in suboptimal range of motion, higher DASH scores and painful arthritic wrist.

It is noteworthy that all the international studies prominently mentions about the successful results of plating in achieving early and better range of motion which definitely improves personal satisfaction of patients which is also significantly proved in our study too.

Another pioneering analysis from our study was the comparison of all functional as well as radiological parameters for each fracture type of Frykman's classification and comparison amongst the modalities for each fracture type. As concluded for the whole study population, the results were in agreement for each fracture type too. In fracture pattern wise comparison too, plating showed better functional as well as radiological outcomes than $\mathrm{k}$-wiring and external fixators.

\section{Conclusion}

With increasing life expectancy and functional demands, it is mandatory to obtain near total function of hand irrespective of type of fracture of lower end radius. To achieve this goal we should classify the fractures pre operatively, if required CT scan should be done for proper planning and reduction of the fracture and fixation using latest implant. It is obvious with the study, anatomical reduction and its maintenance using rigid implants like anatomical plates gives better functional outcome. K-wire fixation can be used for relatively younger age group with better bone quality and less functional demands. External fixator should be reserved for severely comminuted fractures with poor bone quality, functionally low demand patients and poor skin condition pre-operatively.

\section{References}

1. Chung KC, Shauver MJ, Birkmeyer JD. Trends in the United States in the treatment of distal radial fractures in the elderly. J Bone Joint Surg Am. 2009;91(8):1868e1873.

2. Melton LJ III, Amadio PC, Crowson CS, et al. Long-term trends in the incidence of distal forearm fractures. Osteoporos Int. 1998;8(4):341e348.

3. Bengner U, Johnell O. Increasing incidence of forearm fractures: a comparison of epidemiologic patterns 25 years apart. Acta Orthop Scand 1985;56(2):158e160.

4. Arora R, Lutz M, Deml C, et al. A prospective randomized trial comparing nonoperative treatment with volar locking plate fixation for displaced and unstable distal radial fractures in patients sixty-five years of age and older. J Bone Joint Surg Am. 2011;93(23):2146e2153.

5. Ring D, Jupiter JB. Treatment of osteoporotic distal radius fractures. Osteoporos Int 2005;16(suppl 2):S80eS84.

6. Mattila VM, Huttunen TT, Sillanpaa P et al. Significant change in the surgical treatment of distal radius fractures: a nationwide study between 1998 and 2008 in Finland. J 
Trauma. 2011;71(4):939e942; discussion 942e933.

7. Caldwell RA, Shorten PL, Morrell NT. Common Upper Extremity Fracture Eponyms: A Look Into What They Really Mean. J Hand Surg Am 2019;44(4):331-334.

8. Naranje SM, Erali RA, Warner WC, Sawyer JR, Kelly DM. Epidemiology of Pediatric Fractures Presenting to Emergency Departments in the United States. J Pediatr Orthop 2016;36(4):e45-8.

9. Handoll HH, Madhok R. Conservative interventions for treating distal radial fractures in adults. Cochrane Database Syst Rev 2003. CD000314.

10. Rizzo M, Katt BA, Carothers JT. Comparison of locked volar plating versus pinning and external fixation in the treatment of unstable intraarticular distal radius fractures. Hand (N Y) 2008;3(2):111-7.

11. Saving J, Enocson A, Ponzer S, Mellstrand Navarro C. External Fixation versus Volar Locking Plate for Unstable Dorsally Displaced Distal Radius Fractures - A 3-year Follow-up of a Randomized Controlled Study. J Hand Surg Am 2018, doi: 10.1016/jhsa.2018.09.015

12. Marcheix PS, Dotzis A, Benko PE, Siegler J, Arnaud JP, Charissoux JL. Extension fractures of the distal radius in patients older than 50: a prospective randomized study comparing fixation using mixed pins or a palmar fixedangle plate. J Hand Surg Eur 2010;35:646-651.

13. Cuenca J, Martinez AA, Herrera A, Domingo J. The incidence of distal forearm fractures in Zaragoza (Spain). Chirurgie de la main 2003;22:211-215.

14. Karantana A, Downing ND, Forward DP, Hatton M, Taylor AM, Scammell BE et al. Surgical treatment of distal percutaneous methods: a randomized controlled trial. J Bone Joint Surg Am. 2013;95:1737-1744. 333. J Hand Surg Eur 2014;39:249-257.

15. Egol KA, Walsh M, Romo-Cardoso S, Dorsky S, Paksima N. Distal radial fractures in the elderly: operative compared with nonoperative treatment. J Bone Joint Surg (Am). 2010;92:1851-7.

16. Wei DH, Poolman RW, Bhandari M, Wolfe VM, Rosenwasser MP. External fixation versus internal fixation for unstable distal radius fractures: a systematic review and meta-analysis of comparative clinical trials. J Orthop Trauma. 2012;26:386-394. Volume 473, Number 9, September 2015 Distal Radius Meta-analysis 3027

17. Wilcke MK, Abbaszadegan H, Adolphson PY. Wrist function recovers more rapidly after volar locked plating than after external fixation but the outcomes are similar after 1 year. Acta Orthop 2011;82:76-81.

18. Oshige T, Sakai A, Zenke Y, Moritani S, Nakamura T. A comparative study ofclinical and radiological outcomes of dorsally angulated, unstable distal radius fractures in elderly patients: intrafocal pining versus volar locking plating. The Journal of Hand Surgery/ 2007, 32A(9).

19. Goehre G, Otto W, Schwan S, Mendel T, Vergroesen PP, Lindemann- Sperfeld L. Comparison of palmar fixedangle plate fixation with $\mathrm{K}$-wire fixation of distal radius fractures (AO A2, A3, C1) in elderly patients. J Hand Surg Eur 2014;39:249-257.

20. Young Hak, Beom Lee, Jong Baek, Jung Noh, Hyun Gong, Goo Baek. A Randomized Comparison of Volar Plate and External Fixation for Intra-Articular Distal Radius Fractures. J Hand Surg Am 2015, 40, 